\title{
Public Opinion Survey Report on the Construction of the Grand Canal Cultural Belt in Our District
}

\author{
Yuliang Zhu \\ Social and Economic Investigation Team of Gongshu District, Hangzhou 310015, Zhejiang, China \\ Email: 183968828@qq.com
}

\begin{abstract}
Through a public opinion survey on the construction of the canal cultural belt in Gongshu District of Hangzhou, this paper surveyed the residents' awareness, participation and satisfaction of the construction of the canal cultural belt, as well as their cognition and evaluation of the needs of the Grand Canal cultural belt. At the same time, through random surveys of business households and tourists along the route, the hot spots, difficulties and focal points of the construction of the cultural belt are understood. Finally, the residents, business households and tourists along the line put forward various suggestions on the construction of the canal cultural belt from their respective perspectives.
\end{abstract}

Keywords: Grand Canal, cultural belt, construction, public opinion

\section{Introduction}

President Xi Jinping stressed, "The Grand Canal is a precious heritage left to us by our ancestors, and it is a mobile culture, which should be well protected, inherited, and utilized as a whole." ${ }^{[1]} 2019$ marks the 5th anniversary of the successful application for the world heritage of the Grand Canal. To fully understand the residents, tourists and business households' cognition and evaluation of the construction of the Grand Canal cultural belt in our district, the District Bureau of Statistics organized and carried out a public opinion survey recently on the construction of the Grand Canal cultural belt throughout the district. The survey shows that the respondents have a good overall evaluation of the construction of the Grand Canal cultural belt in our district. At the same time, residents, tourists and business households put forward their opinions and suggestions on the construction of the Grand Canal cultural belt from their respective perspectives.

\section{Basic situation of the respondents}

The surveyed communities of the Grand Canal included in this survey are 23 surveyed communities along the canal, involving 500 samples, including 400 residents, 50 tourists and 50 business households.

\subsection{Basic situation of the resident samples}

Among the 400 residents, $10.8 \%$ are $18-29$ years old, $25.0 \%$ are $30-39$ years old, $24.0 \%$ are $40-49$ years old, $24.9 \%$ are 50-59 years old, and 15.3\% are 60-69 years old. In terms of gender, men account for 45.2\% and women account for $54.8 \%$. In terms of educational background, those with junior high school education and below account for $15.3 \%$, those with high school and technical secondary school education account for $29.0 \%$, those with junior college degree account for $20.0 \%$, those with bachelor's degree account for 33.2\%, and those with master's degree and above account for $2.5 \%$.

\subsection{Basic situation of tourist samples}

Among the 50 samples of random intercept interview, $64.0 \%$ come from within the province and $36.0 \%$ come from outside the province. From the perspective of tourism purpose, $66.0 \%$ of tourists are for sightseeing, $22.0 \%$ are for vacationing, $2.0 \%$ are for inspections, and $10.0 \%$ are for other tourism purposes. From the perspective of the number of trips, $32.0 \%$ of the tourists visit for the first time, $34.0 \%$ of the tourists have visited twice, $10.0 \%$ of the tourists have visited 3 times, $24.0 \%$ of the tourists have visited more than 3 times. In terms of the number of days in the scenic spot, $58.0 \%$ of tourists choose one day. Tourists who choose 2 days, 3 days and more than 3 days account for $22.0 \%, 8.0 \%$ and $12.0 \%$ respectively.

\subsection{Basic situation of business household samples}

From the perspective of business types, among the 50 business households, $32.7 \%$ are engaged in meals, $18.4 \%$ are engaged in trade, $4.1 \%$ are engaged in entertainment, $4.1 \%$ are engaged in homestays, and $40.7 \%$ are engaged in other cultural industries. In terms of the number of years of opening, the business households that have opened for 1-3 years are 
the most, accounting for $50.0 \%$; those that have opened for more than 6 years account for $28.0 \%$, those that have opened for $4-6$ years account for $12.0 \%$, and those that have opened for less than 1 year account for $10.0 \%$. From the perspective of whether the business household has online sales, $48.0 \%$ of the business households have online sales, and $52.0 \%$ of the business households do not have online sales. From the perspective of the source of customers, the business households whose source of customers are local residents account for $70.0 \%$, those whose source of customers are foreign residents account for $24.0 \%$, and those whose source of customers are overseas tourists account for $6.0 \%$.

\section{Residents' overall evaluation of the construction of the Grand Canal cultural belt in our district}

On the whole, the interviewed residents have a better understanding of the application for world heritage of the canal and the general situation of the Grand Canal cultural belt in our district, and their participation is good. The overall satisfaction rate of the cultural belt construction is relatively high. The overall satisfaction of residents to the realization of consumption demand of the Grand Canal cultural belt is relatively high. As is shown in Figure 1.

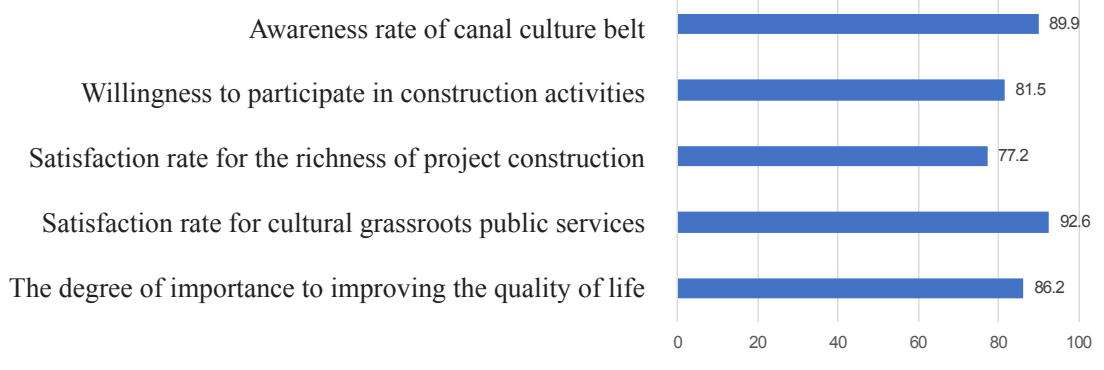

Figure 1. Satisfaction evaluation of the construction of the Grand Canal cultural belt (\%)

\subsection{Evaluation of the understanding of the cultural heritage of the Gongshu section of the canal}

According to the survey, when asked "how much do you know about the the application of Beijing-Hangzhou Grand Canal for world cultural heritage", $22.8 \%$ think that they "know very well" and $61.9 \%$ think that they "know better". The total of the two is $84.7 \%$.

From the specific situation, Gongchen Bridge has become the cultural heritage of the Gongshu section of the canal that leaves the deepest impression on residents. When asked "which section impressed you most about the Gongchen section of the Grand Canal in Hangzhou", 60.4\% choose "Gongchen Bridge Section", accounting for the first place; those who choose "Maiyu Bridge Section (Xinyifang)" ranked second, accounting for 19.3\%; in addition, those who choose "north of Gongchen Bridge" and "south of Maiyu Bridge" account for 12.3\% and 7.5\% respectively; those who do not know account for $0.5 \%$. There are three cultural heritage sites in the Gongshu section of the canal, namely Gongchen Bridge, Fuyi Cang and Qiaoxi Historic District. Judging from the expression of public opinion on the most representative cultural heritage of the Gongshu section of the canal, Gongchen Bridge also ranks first with an absolute advantage of 58.8\%, Qiaoxi Historic District ranks second with $24.0 \%$, and Fuyicang ranks third with $15.0 \%$.

\subsection{Evaluation of the awareness of the construction of the Grand Canal cultural belt}

In the survey, when the interviewed residents are asked "how much do you usually pay attention to the Grand Canal cultural belt", $30.6 \%$ of the interviewed residents express "special concern" and $61.8 \%$ of the interviewed residents express "somewhat concern", which together account for 92.4\%. When asked "how well do you know about the Grand Canal cultural belt", $17.8 \%$ of the interviewed residents say they have "in-depth understanding", and $68.5 \%$ of the interviewed residents say they have "a certain degree of understanding", which together account for $86.2 \%$.

In the survey, when asked "from which ways do you generally learn about the construction of the Grand Canal cultural belt", "television propaganda" "setting up fixed columns in the 'Gongshu Website' and 'Gongshu Release' to promote the special actions of the Grand Canal cultural belt construction" "radio broadcast propaganda" rank the top three, accounting for $67.9 \%, 48.2 \%$, and $37.9 \%$ respectively. In addition, the proportion of "establishing and improving official Weibo and WeChat platforms, and uniformly publishing news and information on the Grand Canal cultural belt" is $37.4 \%$; the proportion of "propagandizing by issuing brochures, setting up display boards, hanging banners, etc. in crowded places" is $36.7 \%$; the proportion of "relying on the community and regularly organizing and carrying out propaganda related to the Grand Canal cultural belt" is $31.4 \%$. 


\subsection{Evaluation of participation in the construction of the Grand Canal cultural belt}

In the survey, when asked " whether you would like to participate in activities about Grand Canal culture (such as Canal Temple Fair, Grand Canal Cultural Festival, Traditional Culture Experience Day)", 71.7\% say they would love to. When specifically asked "what are your favorite canal tourism products", the "museums and handicraft exhibition halls around the Beijing-Hangzhou Grand Canal" rank first with $68.1 \%$. The proportion of "water sports tours" is $50.8 \%$, ranking second. In addition, the proportions of "folk culture of country fairs" "food culture" and "industrial relics of bridge construction historic district" are $43.7 \%, 42.7 \%$ and $37.4 \%$ respectively. When asked "are you willing to participate in the construction of the Grand Canal cultural belt", $36.1 \%$ say they are "very willing", and 56.5\% say they are "relatively willing", which together account for $92.6 \%$. When asked "have you ever visited the museums around the canal (such as the Knife, Scissors and Sword Museum, Umbrella Museum, Fan Museum, Arts and Crafts Museum, Beijing-Hangzhou Grand Canal Museum, etc.)", the proportion of those who have visited is $94.9 \%$.

\subsection{Satisfaction evaluation of the construction of the Grand Canal cultural belt}

In recent years, our district has made every effort to promote the construction of the canal cultural belt and has completed a number of construction projects and supporting facilities, and some projects are also being launched or continued. When asked "which projects are you more interested in", "starting projects such as the Grand Canal Asian Games Park, Canal Bay and Xiangfu Bridge Cultural District, Twenty-Four Solar Terms Park, Warring States Crystal Cup Park, etc." rank first with 78.1\%. "Promoting the construction of the Grand Canal Central Park (Grand Canal Theater) and the Grand Canal Culture and Fashion Publishing Center" ranks second with 77.1\%. The proportions of "Grand Canal Culture and Art Center knot" "completion of renovation of Cangjing Pavilion in Xianning Temple" "The Grand Canal Creation Base of Zhejiang Network Writers Association, Lang Lang Art World and Piano Music classroom” are 45.0\%, $28.9 \%$ and $26.4 \%$, respectively.

In the evaluation of satisfaction with the richness of the construction of the Grand Canal cultural belt project, $31.6 \%$ think they are "very satisfied" and 45.6\% think they are "relatively satisfied", which together account for 77.2\%.

In the current satisfaction evaluation of the 12 business types of the Grand Canal cultural belt project, except for the three business types of hotels and guesthouses, fitness places and other forms of leisure and entertainment, the satisfaction of other business types exceeds $70 \%$. Among them, museums and exhibition halls have the highest satisfaction, which is 93.0\%. Details are shown in the table below.

Table 1. Satisfaction evaluation of various projects of the Grand Canal cultural belt (\%)

\begin{tabular}{|c|c|c|c|c|c|c|}
\hline & $\begin{array}{c}\text { Very satisfied } \\
\text { + relatively } \\
\text { satisfied }\end{array}$ & Very satisfied & $\begin{array}{l}\text { Relatively satis- } \\
\text { fied }\end{array}$ & $\begin{array}{l}\text { Generally } \\
\text { satisfied }\end{array}$ & $\begin{array}{l}\text { Not very } \\
\text { satisfied }\end{array}$ & Dissatisfied \\
\hline Museums, exhibition halls & 93.0 & 60.0 & 33.0 & 6.0 & 1.0 & 0.0 \\
\hline Libraries, bookstores & 79.5 & 41.3 & 38.2 & 18.2 & 2.3 & 0.0 \\
\hline Cinemas, theaters & 78.8 & 36.7 & 42.1 & 18.9 & 2.0 & 0.3 \\
\hline $\begin{array}{l}\text { All kinds of commercial } \\
\text { complexes }\end{array}$ & 76.1 & 36.6 & 39.5 & 22.6 & 0.5 & 0.8 \\
\hline Cultural complexes & 70.2 & 32.7 & 37.5 & 25.4 & 3.6 & 0.8 \\
\hline Fitness places & 64.3 & 29.3 & 35.0 & 30.4 & 4.3 & 1.0 \\
\hline All kinds of theme parks & 72.7 & 37.0 & 35.7 & 22.2 & 4.8 & 0.3 \\
\hline Dining places & 75.0 & 31.9 & 43.1 & 22.4 & 1.8 & 0.8 \\
\hline Hotels and guesthouses & 61.9 & 27.8 & 34.1 & 33.7 & 3.9 & 0.5 \\
\hline Subways and buses & 74.2 & 45.6 & 28.6 & 17.4 & 6.6 & 1.8 \\
\hline Water buses & 82.3 & 52.2 & 30.1 & 15.4 & 2.0 & 0.3 \\
\hline $\begin{array}{l}\text { Other forms of leisure and } \\
\text { entertainment }\end{array}$ & 64.3 & 28.2 & 36.1 & 30.2 & 4.7 & 0.8 \\
\hline
\end{tabular}




\subsection{Residents' cognition and evaluation of the needs of the Grand Canal cultural belt}

\subsubsection{Cultural grass-roots public services (five "give"s and five "enter"s) are highly satisfying}

In terms of providing cultural grass-roots public services in the whole district, it is mainly reflected in five "give"s and five "enter"s, that is, "give movies, give performances, give equipment, give lectures and give exhibitions; enter communities, enter schools, enter construction sites, enter military camps and enter nursing homes". When asked to "make an overall evaluation of cultural grass-roots public services based on your own feelings", $38.6 \%$ of the residents are "very satisfied" and $42.9 \%$ are "relatively satisfied", which together account for $81.5 \%$.

3.5.2 The overall satisfaction with the realization of consumer demand of the Grand Canal cultural belt is relatively high

When asked about "your overall satisfaction with the current consumer demand of the Grand Canal cultural belt", those who are "very satisfied" account for 32.4\%, and those who are "relatively satisfied" account for 46.2\%, which together account for $78.6 \%$. Those who are "generally satisfied" account for $19.1 \%$, those who are "not very satisfied" account for $2.0 \%$, and those who are "dissatisfied" account for $0.3 \%$.

3.5.3 From the perspective of the choice of ways to inherit and promote the Grand Canal culture, the development of characteristic tourism and the industrial chain around the canal stay top two

When asked "which ways do you think can be used to inherit and promote the Grand Canal culture", $66.8 \%$ choose "developing characteristic tourism", 54.0\% choose "developing a cultural industry chain around the canal" and $42.0 \%$ choose "developing the canal food industry". Those who choose "promoting surrounding folk crafts" "displaying in museums and rest pavilions along the canal" "promoting the history and culture of the canal through drama, song and dance" account for $38.0 \%, 37.3$ and $24.3 \%$ respectively. From the perspective of cultural and creative industries, the interviewed residents believe that there are many advantages in cultural and creative industries in our district, which promote the realization of the cultural needs of the Grand Canal. When asked "what do you think are the advantages of the cultural and creative industries around Gongshu Cana", 64.7\% of the interviewed residents say "continuing and publicizing Hangzhou's history and canal culture", and 60.6\% say "creating a livable environment". 50.3\% say "attracting more tourists and promoting the development of tourism"; $46.2 \%$ say "promoting the development of commerce around the region"; $40.9 \%$ say "commodities are creative and memorable".

3.5.4 Residents believe that the construction of the Grand Canal Cultural Belt is of high importance to improve the overall quality of life

When asked "how important do you think the construction of the Grand Canal cultural belt is to improve your overall quality of life", 45.6\% think "very important", and 44.3\% think "relatively important", which together account for 89.9\%; $9.3 \%$ think "generally important" and $0.8 \%$ think "not very important".

3.5.5 Among all kinds of cultural life, what residents expect most is the convenience of cultural facilities, entertainment and fitness

When asked "which options are you most looking forward to about the cultural life of the Grand Canal", $65.8 \%$ choose "it will be easier to find suitable cultural facilities or recreational and fitness venues around"; $58.3 \%$ choose "cinemas, theaters, artistic performances, books, newspapers and magazines will be richer"; 48.7\% choose "movie tickets, performance tickets, and cheaper book prices"; $48.2 \%$ choose "community cultural activities can be richer"; $43.5 \%$ choose "faster Internet speed, lower prices, and more personalized services"; $31.4 \%$ choose "more orderly management of the cultural market".

3.5.6 Regular free opening of the Grand Canal cultural and artistic venues is the main way to meet the residents' cultural consumption needs of the Grand Canal

According to the survey, when asked "how do you think we can better meet the cultural consumption needs of the Grand Canal", 71.5\% choose to "regularly open the Grand Canal cultural and artistic venues for free"; 63.2\% choose to "develop public cultural activities and let more people participate"; 51.9\% choose to "strengthen the infrastructure construction of the Grand Canal cultural belt"; $46.9 \%$ choose to "strengthen innovation, enrich the types of cultural products, and lower the price of cultural products"; $45.1 \%$ choose to "create the Grand Canal cultural brand and increase media publicity"; $34.5 \%$ choose to "guide the establishment of public cultural consumption awareness".

\section{Tourists' cognition and evaluation of the Grand Canal cultural belt}

In this survey, we randomly intercepted and interviewed 50 tourists from inside and outside the province in the three historic districts: Qiaoxi Historic District, Xiaohezhi Street Historic District, and Dadou Road Historic District. The survey of the 50 tourists shows that the tourists are satisfied with the tourism construction of the Grand Canal cultural belt in our 
district in terms of overall and sub-item tourism supporting facilities, but they also put forward shortcomings of the scenic entertainment projects.

The details of the survey are as follows. In the evaluation of the overall satisfaction of this tour, $40.0 \%$ of tourists think that they are "satisfied", and $46.0 \%$ think that they are "relatively satisfied", which together account for $86.0 \%$. In the satisfaction evaluation of the richness of the construction of the Grand Canal cultural belt project, 34.0\% of tourists think that they are "satisfied" and $42.0 \%$ think that they are "relatively satisfied", which together account for $76.0 \%$. In the overall satisfaction evaluation of the surrounding supporting facilities, $42.0 \%$ of tourists think that they are "satisfied", and $46.0 \%$ think that they are "relatively satisfied", which together account for $88.0 \%$. In the evaluation of traffic conditions, $32.0 \%$ of tourists think that they are "satisfied", and $48.0 \%$ think that they are "relatively satisfied", which together account for $80.0 \%$. In the evaluation of food and accommodation conditions, $30.0 \%$ of tourists think that they are "satisfied" and $54.0 \%$ think that they are "relatively satisfied", which together account for $84.0 \%$. In the evaluation of environmental sanitation conditions, $42.0 \%$ of tourists think that they are "satisfied" and $50.0 \%$ think that they are "relatively satisfied", which together account for $92.0 \%$. In the satisfaction evaluation of the safety measures in the scenic spots, $50.0 \%$ of tourists think that they are "satisfied", and $42.0 \%$ think that they are "relatively satisfied", which together account for $92.0 \%$. In the satisfaction evaluation of shopping in the scenic spots, $36.0 \%$ of tourists think that they are "satisfied" and 40.0\% think that they are "relatively satisfied", which together account for 76.0\%. When asked "what is the main shortcoming of the scenic spot", $14.0 \%$ say "natural landscape", 2.0\% say "environmental sanitation", $80.0 \%$ say "entertainment", and 4.0\% say "service quality". See Figure 2.

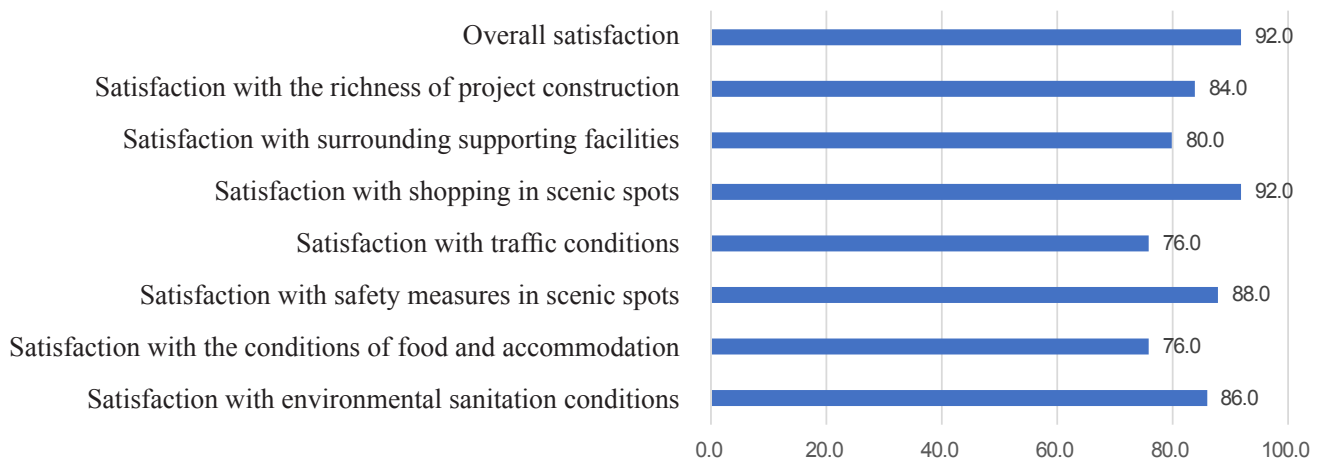

Figure 2. Satisfaction evaluation of tourists on this tour (\%)

In addition, from the perspective of the way to understand scenic spots, the proportion of through the Internet is the largest with $44.0 \%$; the second is through friend introduction, accounting for $42.0 \%$; through travel agency travel brochures accounts for $8.0 \%$; through advertising accounts for $6.0 \%$. Regarding whether they will travel to the canal again, $94.0 \%$ of tourists say they will come again, showing a good effect of returned customers.

\section{The business households' cognition and evaluation of the Grand Canal cultural belt}

In this survey, we also select 50 samples from the business households in the three historic districts mentioned above and conduct a questionnaire survey on them. The survey shows that the interviewed business households are generally satisfied with the business environment and the construction of the Grand Canal cultural belt, but they also made some constructive evaluations from the perspective of their own operations.

\subsection{Satisfaction evaluation}

The survey shows that in the evaluation of the richness satisfaction of the construction project of the Grand Canal cultural belt, $48.0 \%$ of the business households think that they are "satisfied", and $22.0 \%$ think that they are "relatively satisfied", which together account for $70.0 \%$. In the overall satisfaction evaluation of the surrounding supporting facilities, $44.0 \%$ of business households are "satisfied" and $32.0 \%$ are "relatively satisfied", which together account for $76.0 \%$. In the evaluation of the importance of the construction of the Grand Canal cultural belt to the improvement of the overall quality of life of individuals, $62.0 \%$ of business households think it is "very important" and $32.0 \%$ think it is "relatively important", which together account for $94.0 \%$. 


\subsection{Evaluation of operating conditions}

According to the survey, in the evaluation of the importance of the construction of the Grand Canal cultural belt in improving the business environment of stores, $74.0 \%$ of the business households think it is "very important" and $20.0 \%$ think it is "relatively important", which together account for $94.0 \%$. In the evaluation of the driving effect of the construction of the Grand Canal cultural belt in increasing the passenger flow of the stores, $74.0 \%$ of the business households think it is "very important", and $14.0 \%$ think it is "relatively important", which together account for $88.0 \%$. In the evaluation of confidence in future operations, $63.3 \%$ of business households think they are "very confident", and $22.4 \%$ think they are "relatively confident", which together account for $85.7 \%$. In the evaluation of the business environment, $48.0 \%$ of business households think they are "very satisfied" and 32.0\% think they are "relatively satisfied", which together account for $80.0 \%$. The survey also shows that business households are still not satisfied with the current operating benefits. The details are as follows. In the satisfaction evaluation of the overall operating efficiency of the business households, $22.0 \%$ of the business households are "very satisfied", and $38.0 \%$ are "relatively satisfied", which together account for $60.0 \%$. 30\% are "generally satisfied"; $4.0 \%$ are "not very satisfied"; $6.0 \%$ are "dissatisfied".

\subsection{Evaluation of participation}

From the perspective of participation, $67.3 \%$ of the business households participate in related Grand Canal cultural activities such as the Grand Canal Cultural Festival, while $32.7 \%$ of the business households do not participate. When asked "are you willing to participate in the activities related to the construction of the Grand Canal cultural belt", $64.0 \%$ of the business households say "very willing" and 30.0\% say "relatively willing", which together account for $94.0 \%$. This shows that the business households have a strong willingness to participate.

\section{Comments and suggestions}

\subsection{Write articles on heritage protection and inheritance well and tell stories of Gongshu well}

The construction of the Grand Canal cultural belt should adhere to the simultaneous protection and development, and inherit the ancient canal culture. When asked "what do you think is more urgent for our district to promote the construction of the Grand Canal cultural belt", $80.5 \%$ say "the comprehensive management of canal ecology (water treatment, embankment greening)"; 73.4 say "canal heritage protection" $\% ; 62.7 \%$ say "the inheritance and activation of the canal folk culture". Some residents suggest "maintaining the original appearance as much as possible and reducing some overcommercialized shops" "exploring more traditional customs and culture of the canal and letting the tradition flow along the canal" "organizing historical data, clarifying the historical context, and strengthening the existing historical and cultural heritage" "strengthening he protection, development and utilization of existing historical and cultural relics" "establishing geographical indications for well-known historical relics that have disappeared, and displaying relevant information to the public". Qianlongfang, located in Jiangzhangqiao, was originally used for commercial purposes and is no longer in operation. It is recommended to be an open attraction. The "gondolas" (boats) donated by Italy at Qinfeng Bridge have fallen into disrepair and overgrown with weeds. It is recommended that they be protected and repaired. Some residents also suggest strengthening ecological protection, enhancing water quality, and enhancing greening along the canal. It is recommended to replant willows. Canal fishing activities should be strictly monitored to maintain the ecological balance of the canal. Residents suggest that we should go to the grass-roots level to listen to the old people talking about the old people of Gongchen Bridge, dig deep into the cultural heritage of Gongchen Bridge Canal, and tell the story of Gongshu Canal. Residents also put forward some specific suggestions. For example, the pavilion on the north side of the Canal Plaza is recommended to be opened to the outside world, and canal cultural activities or exhibitions are held regularly. In addition, residents believe that the protection of the canal heritage should also listen to public opinions, respect the needs of the people, retain more things left by the old foundation, and learn more from well-protected places. ${ }^{[2]}$

\subsection{Strengthen the propaganda of the Grand Canal culture and increase the participation of the people}

Residents suggest using various tools such as radios, televisions and new technology media to actively publicize and make a good film about the canal (Gongchen Bridge)". Celebrities (in cultural, social, film and television, and other fields) can be regularly invited to interact with everyone in the canal and shoot some TV dramas about the canal. To develop more souvenirs from the Gongshu Canal, use some festivals to increase publicity, increase the time of the event, and expand the influence of the event. Some residents also suggest organizing more cultural activities that are close, convenient and beneficial to the people, so that more ordinary citizens can participate in and experience the Grand Canal culture. 
Some residents also suggest that "diversified development should be made to make culture and arts more approachable and integrate into the lives of ordinary citizens". Residents also suggest that more venues for cultural activities should be added. In addition, personalized activities should also be launched for different groups of people. For example, more activities can be held for children and the elderly. ${ }^{[3]}$

\subsection{Strengthen the construction of supporting facilities in the canal belt to enhance residents' sense of acquisition}

The first is the construction of subway and public transport facilities. Some residents suggest that our district should add subway stations to facilitate travel, such as adding subway stations in Gongbei District. Some residents also present that there are not many bus routes between Qiaoxi and Qiaodong, and they hope to add corresponding buses. Some residents think that water buses should have more stops and more frequent arrangements to facilitate water travel. The second is the construction of entertainment venues. There are few special play facilities for children on both sides of the canal. It is recommended to add special experience areas for children so that children have more play areas. The third is the construction of tourist trails. Some residents say that the road along the coast from Daguan Bridge to Dahu Street Crossing is uneven, and it is recommended to build a stone road similar to the south of Daguan Bridge. After the Xiaohezhi Street Crude Oil Depot is demolished, the landscape tour trail will be completed as soon as possible. The fourth is supporting public construction. Some residents say that there are a lot of residents on the bridge of Langqin Cuiyuan, Yuhangtang River, a tributary of the Grand Canal, who exercise, but there are no public toilets nearby. It is recommended to add public toilet facilities. The fifth is supporting cultural facilities. After the relocation of the district library, there is no large library along the canal. In the survey, residents hope to build libraries, book fairs, book bars and other book reading places to enrich their spiritual world. Some residents also point out that the canal cultural facilities and places in the whole district are too concentrated in the Qiaoxi section, and other sections are not extended enough. They hope to strengthen the construction in the upstream and downstream to form a canal cultural industry chain. ${ }^{[4]}$

\subsection{Create a "Canal Tour" tourism brand to enhance tourists' sense of experience}

The tourists participating in the survey all come to play because of the historical and cultural reputation of the Grand Canal, and experience the historical origin and cultural value of the Grand Canal. However, there are also problems such as scattered historical sites, insufficient transportation, and insufficient unified theme. The first is to create a "Canal Tour" boutique tourism route, forming a tourism brand with distinctive themes and a unified style. Some tourists suggest connecting Gongchen Bridge, Xiaohezhi Street, Fuyi Cang and other major scenic spots with a special "boat tour", which is convenient for tourists from other places. Local people are more familiar with the existing forms of water buses, and cruise ships can increase tourists' sense of participation. The second is to enrich the content of "Canal Tour" and increase the number of entertainment items. Some tourists point out that "as a world cultural heritage, the Grand Canal has rich tourism resources, complete types and distinctive features, so it has tourism development value." It is recommended to set up more entertainment projects to attract tourists. It is recommended to add a traditional cultural interactive experience tourism project with Hangzhou characteristic arch villa flavor. It is recommended to build a high-quality canal tourism route, which is divided into a whole. The third is to strengthen cultural propaganda on the Grand Canal and organize more cultural tourism activities. Some tourists think that the promotion of the Grand Canal culture should be broadcasted along the coast, and the scenic spots will distribute more promotional leaflets. Some tourists suggest that more canal folk activities should be organized to make canal tourism unique and reflect a different style. For water tourism, tourists are recommended to add cruise ship docks and cruise lines during working days. ${ }^{[5]}$

\subsection{Optimize the business environment of the canal cultural belt and enhance investment attractiveness}

Most of the business households along the canal recognize the brand effect of the Grand Canal and are optimistic about the prospects of tourism development and utilization, but there are still "small, scattered and partial" situation. They hope the government will give active guidance and effective integration. The first is to integrate resources and develop together. Some business households suggest using well-known brands in the Grand Canal cultural belt to integrate resources and strive to make new contributions to the construction of the Grand Canal cultural belt. Some business households suggest increasing the continuity of visits to several historic districts. At present, due to the distance between them (mainly on foot), the ride is not very convenient. The cruise ships do not stop at Xiaohezhi Street and Dadou Road. Use scenic buses or water buses to connect the traffic of several scenic spots in series, from point to surface. Some business households suggest that "the Grand Canal culture can penetrate into businesses, integrating scenic spots and business 
resources, and allowing businesses to participate in the Grand Canal culture. Construction". The second is to highlight features and strengthen supporting facilities. Some business households believe that "the characteristics of each business should be prominent, and there is still a lack of obvious intersection guidelines and cultural profiles." Some business households suggest that the construction of commercial supporting facilities, such as buses, toilets, and parking lots, should be strengthened. Some business households on Xiaohezhi Street report that "the public toilets are too far away and the house numbers are arranged in a mess, which is not very convenient for tourists." The third is to increase passenger flow and improve efficiency. Some business households report that "the operating rent and income do not match" "tourists stay in the merchants for a short time, and look forward to holding more activities related to the canal culture to increase the flow of people" "propaganda needs to be strengthened, and the effect on drainage is not obvious". Some business households in Xiaohezhi Street also conduct an in-depth analysis of their business conditions. They believe that "the traffic is inconvenient, the publicity is not enough, the introduction of foreign tourists is not enough, the management is not unified, the shops are simplistic, the rents are rising, and they lack interest and novelty. This leads to a small number of returned customers and bad business during working days." It is hoped that the neighborhood will do more publicity to increase the passenger flow, and at the same time, it can be more considerate of the business owners, reduce the burden more, and improve the benefits of the business households. ${ }^{[6]}$

\section{References}

[1] The General Office of the Central Committee of the Communist Party of China and the General Office of the State Council issued the "Plan for the Protection, Succession and Utilization of the Grand Canal Culture". Urban Planning Newsreport. 2019; (10): 4-5.

[2] Zhou Wei. Investigation on the Status Quo and Countermeasures of Using Canal Heritage to Promote the Construction of the Grand Canal Cultural Belt in Suzhou. Youth Times. 2019; (23): 130-131.

[3] Shao Bo, Qian Shenghua. On the Protection, Inheritance and Utilization of Cultural Relics in the Construction of the Grand Canal Cultural Belt. Journal of Liaocheng University (Social Sciences Edition). 2019; (1): 10-17.

[4] Jia Bingqiang. Construction Principles and Path Selection of the Grand Canal Cultural Belt. Canal Studies. 2018; (2): 196-206.

[5] Hao Feixue. On the Construction of Henan Grand Canal Cultural Belt. Journal of Anyang Normal University. 2018; (3): $42-45$.

[6] Ge Jianxiong. On the History of the Grand Canal and the Construction of the Grand Canal Cultural Belt. Jiangsu Social Sciences. 2018; (2): 126-129. 